\title{
Possibilidades e Limitações das Simulações Computacionais no Ensino da Física
}

(Possibilities and Limitation of Computer Simulations in Physics Teaching)

\author{
Alexandre Medeiros \\ Departamento de Física e Matemática, \\ Universidade Federal Rural de Pernambuco, Recife, PE \\ Cleide Farias de Medeiros \\ Departamento de Educação, \\ Universidade Federal Rural de Pernambuco, Recife, PE
}

Recebido em 3 de abril, 2002. Aceito em 12 de abril, 2002.

\begin{abstract}
Este artigo aborda a importância das animações e das simulações no ensino da Física. Uma apresentação das afirmações de alguns de seus defensores é contrastada com as argumentações de parte relevante dos seus críticos. O propósito do artigo não é defender o abandono da Informática na Educação, mas sim encorajar uma visão mais crítica e equilibrada dela. Desta forma, são discutidos os fundamentos educacionais e epistemológicos que existem subjacentes às linhas de argumentação apresentadas. A importância dos pressupostos e dos limites de validade das teorias é posta em destaque como uma forma de pôr em relevo aquilo que fundamenta as simulações computacionais utilizadas no ensino da Física. O texto conclui apontando a importância de não se concentrar o ensino da Física exclusivamente na veiculação de informações, mas de ter-se em mente a construção do conhecimento em um contexto mais amplo que englobe os conteúdos e os seus processos de construção.
\end{abstract}

This article approaches the importance of computer animation and simulations in the teaching of physics. A contrast is made between assertions of its defenders and relevant part of its critic disapproval. The aim of this paper is not to claim the abandonment of informatics in education, but instead to encourage a more critical and well-balanced point of view. Thus, educational and epistemological foundations underlying the argumentation of both sides are discussed. The importance of theoretical assumptions and limits of validity is exhibited as a means to enhancing the foundations of computer simulations utilised in physics teaching. The text concludes pointing out the importance of teaching physics by avoiding to exclusively concentrate on the transmission of information and, instead, bearing in mind the construction of knowledge in a wide context which incorporates as contents as their processes of development.

\section{A Informática no Ensino da Física}

Nas últimas duas décadas, as utilizações da Informática na Educação têm experimentado um enorme avanço no seu potencial e na sua diversidade de usos. Em países desenvolvidos, já em 1996, Baser observava que aproximadamente $90 \%$ dos laboratórios de pesquisa em Física eram assistidos por computadores, e que os laboratórios de ensino caminhavam na mesma direção. Parece sensato, portanto, que sejam feitas reflexões sobre as possibilidades, as vantagens e as desvantagens de um processo tão acelerado.
Como toda essa corrente de inovações começou e qual a sua relação com a corrente mais ampla da Tecnologia Educacional?

Como assinala Oppenheimer (1997), a revolução da Informática Educacional faz parte de uma história mais longa da Tecnologia da Educação. Desde o início do século $\mathrm{XX}$, várias ondas tecnológicas inovadoras têm assolado a Educação com promessas e perspectivas mirabolantes. Já em 1922, Thomas Edison, referindose ao cinema, afirmava que "as figuras em movimento estão destinadas a revolucionar o nosso sistema educacional. Em poucos anos, elas suplantarão amplamente senão inteiramente, o uso dos livros didáticos"(apud 
Oppenheimer, ibid). Embora uma tal predição não tenha se confirmado, afirmativas semelhantes foram feitas, em outras ocasiões, sobre as possibilidades educacionais de outros meios tecnológicos. Em 1945, por exemplo, William Levenson afirmou que "aproxima-se o tempo em que rádios portáteis serão tão comuns nas salas de aula quanto os quadros-negros" (id, ibid). Expectativas semelhantes foram alardeadas em relação à televisão, aos projetores de filmstrips, slides, filmloops e aos retroprojetores, aos gravadores de áudio, ao super -8 , ao vídeocassete e às calculadoras. Todas essas maravilhas tecnológicas tiveram o seu ciclo de promessas e expectativas ousadas, seguidas, entretanto, por um certo desencanto. Os insucessos educacionais ocorridos e as dificuldades em atender as expectativas iniciais foram sempre creditados ao despreparo dos professores, às inadequações das escolas, à falta de verbas e coisas assim. Mesmo nos países desenvolvidos, quando, após programas de treinamento e obtenção de fundos, os problemas continuaram a existir, dúvidas passaram a ser lançadas sobre as tão propaladas capacidades revolucionárias de todos aqueles aparatos tecnológicos. O aprofundamento do questionamento do uso de tais aparatos na Educação foi, entretanto, sempre estancado pelo aparecimento de uma nova e promissora tecnologia fazendo com que o ciclo recomeçasse com novas e renovadas expectativas. Por mais que se fique fascinado com os avanços e as possibilidades da Informática Educacional, é conveniente lembrarmos que os seus desdobramentos fazem parte do mesmo ciclo de Tecnologias da Educação acima referido. Por isso, é preciso analisarem-se, criticamente, os seus horizontes.

$\mathrm{Na}$ atualidade, a Informática tem uma aplicação muito diversificada no ensino da Física, sendo utilizada em medições, gráficos, avaliações, apresentações, modelagens, animações e simulações (Reuch, 1996; Kocijancic, 1996; Rogers, 1996; Marino, Violino \& Carpignano, 1996; Martins, Pereira \& Martins, 1996; Zoechling, 1996; dentre outros).

Alguns defensores mais entusiastas da Informática no ensino da Física têm alegado que, apesar de existirem dúvidas sobre as vantagens do uso de computadores para o desenvolvimento da personalidade, a sua utilidade no campo educacional do desenvolvimento do pensamento lógico da Física seria inquestionável (Vrankar, 1996). Mesmo tais pesquisadores admitem, porém, que equívocos na confecção dos softwares devidos a uma certa falta de cuidado ou mesmo a uma falta de conhecimento em Física podem ocorrer e conduzir as crianças a pensarem de modo incorreto e, conseqüentemente, a não compreenderem a natureza (Id, Ibid).

Questionamentos mais profundos da utilização da Informática no ensino da Física vão além da denúncia da existência de possíveis equívocos na elaboração dos softwares. É preciso assinalar-se que a simples utilização da Informática não garante que os estudantes tenham uma boa aprendizagem. Como Pintó \& Gómez (1996) alertam, toda experiência proposta aos estudantes tem, intencionalmente ou não, uma abordagem que corresponde a esquemas conceituais, epistemológicos, pedagógicos e psicológicos. Refletir, portanto, sobre as possibilidades e limitações da Informática no ensino da Física equivale a analisarem-se as afirmativas dos seus defensores e dos seus críticos buscando-se a fundamentação das suas argumentações. Este presente trabalho é uma tentativa de ocupar, ainda que parcialmente, este espaço de análise.

\section{Possibilidades das simulações computacionais no ensino da Física}

O ensino da Física nas escolas e nas universidades não tem parecido ser uma tarefa fácil para muitos professores. Uma das razões para essa situação é que a Física lida com vários conceitos, alguns dos quais caracterizados por uma alta dose de abstração, fazendo com que a Matemática seja uma ferramenta essencial no desenvolvimento da Física. Além disso, a Física lida com materiais que, muitas vezes, estão fora do alcance dos sentidos do ser humano tais como partículas subatômicas, corpos com altas velocidades e processos dotados de grande complexidade. Uma tal situação, freqüentemente, faz com que os estudantes se sintam entediados ou cheguem mesmo a odiarem o estudo da Física (Soegeng, 1998; Trampus \& Velenje, 1996).

Numa tentativa de dar conta dessa situação problemática, os professores têm freqüentemente utilizado o recurso ao real concreto e às imagens como um complemento ao uso das linguagens verbal, escrita e da Matemática. Neste sentido, os livros-texto de Física têm recorrido, crescentemente, ao uso de um grande número de ilustrações, muitas das quais referentes a fenômenos dinâmicos. A dificuldade, porém, de representar movimentos e processos através de ilustrações estáticas é algo que não deve ser subestimado. Para contornar esta dificuldade de representação visual, os livros têm utilizado alguns truques como o de representar situações iniciais e finais de um processo por uma série de gravuras em diferentes instantes de tempo ou mesmo apelando para o uso de fotografias estroboscópicas. Tem sido, igualmente, utilizado o recurso de mostrar objetos em movimento com a adição de várias linhas na direção da velocidade ou de representar carros desacelerados com deformações exageradas dos pneus ou ainda de desenhar objetos velozes com linhas difusas e assim por diante. Imagens apresentadas deste modo precisam, entretanto, ser animadas nas mentes dos leitores. A experiência tem mostrado que em muitos casos essas ilustrações não têm sido de grande ajuda. O auxílio gestual provido pelos professores para 
a interpretação dessas imagens em sala de aula, assim como as suas ilustrações adicionais no quadro-negro, não têm sido também de grande eficiência. Esses gestos e ilustrações auxiliares podem parecer claros para aqueles que conheçam bem o fenômeno em causa; mas podem parecer incompreensíveis para outros. Além disso, desenhos no quadro-negro tomam muito tempo e não são tarefas de fácil execução. Os defensores da informática no ensino da Física têm apontado o uso de animações por computadores como uma solução para tais problemas. Alguns têm mesmo advogado que os livros-texto de Física deveriam vir acompanhados por CDs contendo hipertextos repletos de animações (Likar \& Kosuh, 1996).

Simulações computacionais vão além das simples animações. Elas englobam uma vasta classe de tecnologias, do vídeo à realidade virtual, que podem ser classificadas em certas categorias gerais baseadas fundamentalmente no grau de interatividade entre o aprendiz e o computador (Gaddis, 2000). Tal interatividade consiste no fato de que o programa é capaz de fornecer não apenas uma animação isolada de um fenômeno em causa; mas, uma vasta gama de animações alternativas selecionadas através do input de parâmetros pelo estudante. Desta forma, por exemplo, para ilustrar o movimento de um projétil, uma simulação computacional permite ao estudante a escolha de parâmetros relevantes tais como a velocidade inicial e o ângulo de tiro, para os quais o programa fornece as respectivas animações geradas a partir de grandes bancos de dados. Evidentemente, qualquer simulação está baseada em um modelo de uma situação real, modelo este matematizado e processado pelo computador a fim de fornecer animações de uma realidade virtual. A construção, portanto, de uma simulação computacional pressupõe, necessariamente, a existência de um modelo que lhe dá suporte e que lhe confere significado.

As simulações podem ser vistas como representações ou modelagens de objetos específicos reais ou imaginados, de sistemas ou fenômenos. Elas podem ser bastante úteis, particularmente quando a experiência original for impossível de ser reproduzida pelos estudantes. Exemplos de tais situações podem ser uma descida na Lua, uma situação de emergência em uma usina nuclear ou mesmo um evento histórico ou astronômico (Russel, 2001). Experimentos perigosos ou de realizações muito caras assim como os que envolvam fenômenos muito lentos ou extremamente rápidos estão, também, dentro da classe de eventos a serem alvos prioritários de simulações computacionais no ensino da Física (Snir et al, 1988).

Do ponto de vista educacional, uma das deficiências clássicas do sistema de ensino tradicional tem sido a dificuldade de prover as necessidades individuais dos estudantes. Este tem sido um obstáculo central para o desenvolvimento de uma educação efetiva desde os tempos em que a demanda por um ensino universal levou à formação de currículos bem estruturados, grandes escolas e salas de aula. Dentre as buscas de solução para esta problemática, o computador se insurge como uma alternativa educacional desacreditada por alguns críticos e apoiada por numerosos adeptos. Não é de hoje que o uso de computadores tem sido apontado como uma forma de retirar do professor a necessidade de ensinar aos seus estudantes os mesmos materiais, de um mesmo modo e ao mesmo tempo (Smith, 1982).

Essa crença na capacidade do computador poder prover condições ideais para um ensino personalizado tem levado vários pesquisadores a desenvolverem simulações de fenômenos físicos na esperança de que seus estudantes possam trabalhar sobre problemas seguindo os seus próprios ritmos individuais. Um exemplo de simulação elaborada, deliberadamente, com tal objetivo pode ser encontrado em um programa para demonstrar a dinâmica de circuitos elétricos fundamentais e desenvolver nos estudantes a habilidade de raciocinar de forma sistêmica e estruturada, mediante a utilização de softwares alegadamente de grande potencial interativo (Vold, Gjessing \& Hernes, 1996).

Outras simulações computacionais, elaboradas para o ensino da Física, podem ser encontradas nos trabalhos de vários pesquisadores. Trampus \& Velenje (1996), por exemplo, desenvolveram um programa para simular linhas de força para diferentes distribuições de cargas. Uma vez tendo o estudante escolhido uma dentre certas distribuições disponíveis, e assinalado um ponto específico para uma carga de prova, o computador representava graficamente as linhas de força e a força atuando sobre a referida carga de prova. De modo semelhante, Snoj (1996) desenvolveu simulações computacionais com o objetivo de fornecer explicações rápidas e simples para o fenômeno da difração. Escolhendo dentre três tipos de aberturas sobre as quais ondas planas incidiam, o computador fornecia imagens dos padrões de difração obtidos para uma tela distante. Snoj fez questão de assinalar que os seus experimentos virtuais mostravam uma boa concordância com os resultados de experimentos reais realizados pelos seus estudantes. Este casamento da realização de experimentos reais com simulações computacionais tem sido seguido por muitos pesquisadores e sido alvo de intenso debate.

Seguindo essa mesma linha de comparação entre simulações e experimentos reais, Kamishina (1996) desenvolveu uma simulação para o ensino da Física, em nível universitário, referente ao estudo de oscilações não muito fáceis de serem entendidas pela complexidade matemática de suas descrições. O complexo conceito de entropia, por sua vez, foi o alvo de uma outra simulação elaborada por Sperandeo-Mineo (1996) para dar conta do ensino de uma abordagem estatística da segunda lei da Termodinâmica. Nos últimos anos, a produção de simulações para o ensino da Física, muitas das quais disponibilizadas na Internet, tem-se tornado uma verdadeira 'coqueluche'. Apesar do número crescente de 
seguidores desta vertente da utilização da Informática no ensino da Física, os objetivos e os fundamentos das simulações continuam ainda sendo alvo de acesas discussões.

Muitas têm sido as vantagens apontadas para a utilização das simulações no ensino das ciências pelos seus defensores. Em recente trabalho de doutorado, Gaddis (2000) fez um amplo levantamento das principais justificativas apontadas para tal uso. A análise de tais posicionamentos constitui-se em um importante campo de pesquisa da educação científica atual. Dentre tais posicionamentos, podemos assinalar os seguintes benefícios, além dos acima apontados, supostamente trazidos pelas simulações computacionais no ensino da ciência:

reduzir o 'ruído' cognitivo de modo que os estudantes possam concentrar-se nos conceitos envolvidos nos experimentos;

fornecer um feedback para aperfeiçoar a compreensão dos conceitos;

permitir aos estudantes coletarem uma grande quantidade de dados rapidamente;

permitir aos estudantes gerarem e testarem hipóteses; engajar os estudantes em tarefas com alto nível de interatividade;

envolver os estudantes em atividades que explicitem a natureza da pesquisa científica;

apresentar uma versão simplificada da realidade pela destilação de conceitos abstratos em seus mais importantes elementos;

tornar conceitos abstratos mais concretos;

reduzir a ambigüidade e ajudar a identificar relacionamentos de causas e efeitos em sistemas complexos;

servir como uma preparação inicial para ajudar na compreensão do papel de um laboratório;

desenvolver habilidades de resolução de problemas;

promover habilidades do raciocínio crítico;

fomentar uma compreensão mais profunda dos fenômenos físicos;

auxiliar os estudantes a aprenderem sobre o mundo natural, vendo e interagindo com os modelos científicos subjacentes que não poderiam ser inferidos através da observação direta;

acentuar a formação dos conceitos e promover a mudança conceitual.

Diante de um quadro tão otimista sobre as possibilidades educacionais das simulações no ensino da Ciência, faz-se necessário questionarem-se quais as limitações existentes para a consecução delas. Há de se observar, certamente, que por trás de todo este decantado otimismo há uma linha de argumentação a ser devidamente examinada em sua mais fundamental base de sustentação. Cumpre-se analisar não apenas as alegadas vantagens educacionais; mas, igualmente, as bases epistemológicas das simulações computacionais que dão sustento aos prodigiosos benefícios que elas poderiam trazer para o ensino, no dizer de seus mais ardorosos defensores.
Há de se observar, sobretudo, que enquanto muitos educadores conferem às simulações poderes educacionais quase miraculosos, outros tantos continuam ainda avessos às mais simples introduções da Informática no ensino da Ciência. Entre a euforia e o pânico existe, portanto, todo um campo de argumentações a ser devidamente explorado e criteriosamente examinado com o necessário rigor analítico.

\section{Limitações das simulações computacionais no ensino da Física}

Uma grande ênfase é dada comumente ao fato de que novas tecnologias educacionais, tais como as simulações computacionais, possibilitaram uma mudança radical no modo de se ensinar a Física. Em muitos aspectos, essa mudança equivale à quebra de um antigo paradigma educacional baseado em aulas expositivas e laboratórios tradicionais. Pouca referência é feita, entretanto, aos perigos que uma tal mudança educacional pode, igualmente, trazer consigo. O excesso de entusiasmo acerca das novas tecnologias pode obscurecer o fato de que, com o seu uso, alguns conhecimentos e habilidades importantes estejam sendo inadvertidamente perdidos (Miro-Julia, 2001). Há um grande risco implícito na adoção acrítica das simulações no ensino da Física, pois elas apresentam certas desvantagens, algumas vezes negligenciadas. Seria primordial notar-se que um sistema real é freqüentemente muito complexo e as simulações que o descrevem são sempre baseadas em modelos que contêm, necessariamente, simplificações e aproximações da realidade. Uma tal modelagem de um sistema físico é crucial para que as simulações construídas possam constituir-se em boas aproximações da realidade (Bergqvist, 2000). Existe uma diferença significativa entre o ato de experienciar-se um fenômeno através de um experimento real e de uma simulação computacional. Se tal diferença não for percebida, as simulações podem, por vezes, comunicar concepções do fenômeno opostas àquelas que o educador pretendia veicular com o seu uso, como a pesquisa educacional tem mostrado (Verbic, 1996).

As modernas técnicas computacionais têm tornado as representações visuais e simulações computacionais fáceis e verdadeiramente espetaculares. Ao mesmo tempo, contudo, elas têm criado uma tendência perigosa de um uso exagerado de animações e simulações considerando-as como alternativas aos experimentos reais, como se tivessem o mesmo status epistemológico e educacional. Destacando a importância do realismo e trabalhando com estudantes de Engenharia num laboratório assistido por computador, Edward (1997) observou que as simulações mostravamse menos efetivas do que os experimentos reais. A 
necessidade, entretanto, de um certo realismo nas simulações não é tarefa simples como possa parecer à primeira vista. Pressupostos contidos nas necessárias simplificações que fundamentam os modelos, nos quais as simulações estão baseadas, passam freqüentemente desapercebidos pelos estudantes e mesmo por muitos professores.

É verdade que uma boa simulação pode comunicar melhor do que imagens estáticas, ou mesmo do que uma seqüência delas, idéias sobre movimentos e processos em geral. Nisso se fundamenta, basicamente, a decantada superioridade das representações computacionais àquelas contidas nos livros didáticos. Inferirse daí, entretanto, que as simulações seriam ao menos equiparáveis aos experimentos reais, constitui-se em um enorme equívoco. É preciso estar em alerta para o fato de que essa arma poderosa pode servir, paradoxalmente, também, para comunicar imagens distorcidas da realidade com eficiência igualmente maior do que a das figuras estáticas. Uma animação não é, jamais, uma cópia fiel do real. Toda animação, toda simulação está baseada em uma modelagem do real. Se essa modelagem não estiver clara para professores e educandos, se os limites de validade do modelo não forem tornados explícitos, os danos potenciais que podem ser causados por tais simulações são enormes. Tais danos tornarse-ão ainda maiores se o modelo contiver erros grosseiros. A nossa própria experiência educacional nos tem mostrado vários casos nos quais estudantes, por vezes talentosos, têm sido ludibriados pela beleza e pelo fascínio da realidade virtual em certas simulações. Em um caso, por exemplo, pudemos observar o encanto de um estudante com uma simulação computacional que representava um tubo de raios catódicos. Ao serem injetados diferentes parâmetros de tensão no sistema, podiam ser observadas belíssimas imagens do brilho das ampolas. Nosso estudante, fascinado, afirmou: "Isso é certamente melhor, mais barato e mais fácil de manipular do que um experimento real. Podemos ver, com clareza, todos os efeitos provocados pela variação da tensão elétrica no tubo. Além disso, a simulação torna evidente que os raios catódicos recebem tal nome pois emanam diretamente do catodo".

Apesar de compartilharmos com o nosso estudante a impressão de encanto sobre a beleza das imagens, ficamos atônitos com o 'conhecimento' que ele havia inferido daquela bela, porém infeliz, simulação. A semelhança com o real extinguia-se na beleza do fenômeno exibido. Por mais que variássemos os parâmetros referentes à tensão elétrica na simulação em causa, ela jamais exibia qualquer espaço escuro, dentro do tubo, que interrompesse a trilha dos raios catódicos. Naquela realidade virtual, não existia o espaço escuro de Crookes, lugar principal da formação de plasma e origem dos raios catódicos no experimento real. Outros espaços escuros mais sutis, como o de Aston, evidentemente, também não eram exibidos. Perguntamos ao nosso es- tudante: mas onde estão os espaços escuros? Não há uma forma de variar a tensão para que eles apareçam? A resposta foi: 'Já tentei, eles não aparecem. Mas, isso é só um detalhe sem grande importância. Mais importante, para mim, é o aspecto realistico desta simulação com que pudemos fazer o aluno ver que os raios catódicos se originam de fato no catodo'. Chocados com aquela impressão, fizemos ver ao nosso estudante que aquela não era absolutamente uma questão menor; mas, ao contrário, uma questão crucial na compreensão do fenômeno. As regiões escuras, contidas na direção dos raios catódicos, eram, na realidade, as fontes principais de emanação daqueles raios e não o catodo em si mesmo como mostravam aquelas belas imagens da simulação. Em outras palavras, o aspecto visual era encantador; mas a simulação havia sido construída com base em um modelo com simplificações exageradas, ou melhor, com graves equívocos. E aí residia o seu maior perigo e aparente aspecto real. Havia um modelo subjacente à simulação e este não estava claro para o estudante que tomava, assim, os equívocos veiculados por uma tal simulação como os aspectos demonstrativos de um fenômeno real. Em outras ocasiões, pudemos observar diferentes exemplos de simulações igualmente belas e não menos equivocadas. É difícil avaliar o seu potencial destrutivo sobre a mente desavisada de um possível aprendiz. Projéteis que eram lançados a distâncias variadas, com ângulos de tiros diversos, eram visualizados em simulações nas quais se podia sempre perceber o aspecto parabólico das trajetórias. Alcances que podiam ser checados contra uma teoria elementar já conhecida em nível médio. Nosso estudante, encantado, afirmou: "Veja, podemos fazer o estudante testar vários parâmetros, obter os alcances e comparar com a teoria ensinada. Ele vai ver, com os próprios olhos, que a teoria funciona, mesmo. Que a teoria é real". Para dar ênfase à sua afirmação, colocou alguns parâmetros no seu 'mágico' software, obtendo quase que instantaneamente o traçado de uma bela parábola e o valor numérico do alcance: $300 \mathrm{Km}$. Disse o nosso estudante, "veja, professor, não é lindo? Não tem quem não entenda. O computador faz mágicas e torna tudo mais fácil. Pode checar com as fórmulas; o alcance dá mesmo $300 \mathrm{~km}$ ". Mais uma vez, ficamos atônitos com o injustificado fascínio daquele outro estudante com aquelas equivocadas modelagens e objetamos:

- Mas, já lhe ocorreu que isto pode estar completamente errado?

Como assim, professor? O senhor está dizendo que o computador errou? Pode checar com as equações. Eu já fiz isso para esses valores; dá certo!

- Dá certo, como?

Dá certo! Dá certo! O resultado do computador é o mesmo da teoria.

E o que é que isso prova?

Ora, prova que está certo, que o experimento real dá isso mesmo, nem precisa fazer. 
Pois, faça. O resultado está errado.

Como assim, professor? Não estou entendendo. O senhor quer dizer que as equações também estão erradas?

- Não é que estejam erradas. Elas simplesmente têm contextos de validade. O modelo tem que ser razoável com a natureza. E essas equações que você usou parecem estar subjacentes a esta linda simulação, a qual, portanto, também passa a ter o mesmo contexto de validade. Esta teoria, como toda teoria, é construída baseada em pressupostos simplificadores da realidade. $300 \mathrm{Km}$ é uma distância enorme para ser atingida por um tiro na superfície da Terra. Para esta distância, o projétil tem que subir muito e em alta velocidade. Além disso, a curvatura da Terra não poderá ser ignorada assim como a resistência do ar e a variação da aceleração da gravidade, como esse modelo simples ignorou. Para levar em conta todos esses fatores complicadores, que nesse caso não poderão ser ignorados, teremos que utilizar equações diferenciais muito mais complexas que essas equações que você escreveu aí.

- Quer dizer, então, que essas equações não valem para este caso?

- Exatamente. Elas só valem para um mundo simplificado de projéteis mais lentos, que não sobem muito e nem vão muito longe.

- Mas... e como fica o computador? Ele é de última geração e o software foi feito usando a última versão do Director; usando, além disso, imagens feitas na última versão do 3-D Studio.

- E daí? Está errado, mesmo assim. Veja lá, essa máquina não pensa, apenas calcula seqüencialmente, e a toda velocidade, o que você mandar. E, convenhamos, já é muito. Mas, não é demais! Nem ela, nem esses softwares com nomes pomposos em inglês, nem a simulação que resultou disso tudo sabem Física nenhuma. A Física estava na mente de quem fez o programa e o autor equivocou-se, apesar de haver produzido um belo espetáculo visual. O valor de qualquer simulação está condicionado ao modelo, à teoria física utilizada em sua construção. Tanto a teoria como evidentemente o software, que está baseado nela, tem contextos de validade que dependem dos pressupostos utilizados. É inegável que as imagens exibidas parecem com as de um filme, parecem com o real; mas apenas parecem. Ignorar os pressupostos embutidos e guiar-se pelo fascínio das aparências ilusórias é como confundir uma tomada de corrente com o focinho de um porco: ambos são redondos e têm dois buraquinhos; mas você não pode ligar esse seu computador no focinho de um porco, pode? Portanto, cuidado com as aparências!

- Risos... .

As cenas acima relatadas seriam cômicas, se antes não fossem trágicas. Confundir-se o virtual com o real, movido pelas aparências ilusórias, é um terrível perigo educacional e epistemológico. Muitas situações semelhantes às acima descritas poderiam ser igualmente mencionadas; mas não serão relatadas neste breve artigo. Retomemos, em seu lugar, as considerações mais gerais a respeito das limitações das simulações computacionais. Como alerta Vedelsby (1996), reportandose ao uso educacional das simulações, os modelos, as simplificações e as idealizações constituem partes muito importantes bem como ferramentas fundamentais em nossa descrição do complexo mundo físico em que vivemos. Um bom modelo em Física é simples e capaz de fazer boas predições. Ele descreve e explica as partes principais dos fenômenos com os quais está relacionado e para os quais foi desenvolvido e é a mais importante ferramenta na compreensão dos resultados dos futuros experimentos. Desta forma, uma parte crucial da aprendizagem da Física é fazer com que os nossos estudantes compreendam e apreciem o conceito de um modelo, o que eles significam, para que foram construídos, seus pressupostos simplificadores e seus limitados contextos de validade. Resistores e lâmpadas incandescentes, por exemplo, são elementos comuns em circuitos elétricos e em simulações computacionais de circuitos elétricos elementares em um nível introdutório. Freqüentemente e de forma bastante simplificada, resistores e lâmpadas são assumidos como tendo, ambos, um comportamento linear, embora a lâmpada, certamente, não o tenha, o que pode tornar-se óbvio mesmo quando os mais simples experimentos reais sejam realizados. Em simulações, entretanto, lâmpadas são vistas freqüentemente variando o seu brilho como ilustrações fascinantes da lei de Ohm. Seria de questionar-se se a aplicação da lei de Ohm para um componente não linear, como uma lâmpada, não seria algo um tanto peculiar ou mesmo um modo desnecessário de tratarem-se os fundamentos da Física. Seria de se perguntar o que um estudante teria a aprender de um tipo de simulação como esta. Seria isso uma boa Física ou seria isso mesmo Física?

Para muitos estudantes, a Física é apenas um amontoado de fórmulas usadas para resolver problemas. E a resolução de problemas consiste apenas em escolher as equações apropriadas, substituir os números e calcular as incógnitas. Mas, como lembra Schecker (2001), os físicos acreditam, com justa razão, que o poder da Física consiste em descrever uma grande variedade de fenômenos com um conjunto muito limitado de leis e princípios fundamentais. Os estudantes, freqüentemente, não percebem a distinção entre as poderosas ferramentas da Física, seus conceitos, princípios e leis fundamentais e os truques, os casos especiais nos quais, por exemplo, certas funções apropriadas descrevem formas especiais de movimento. Desta forma, leis fundamentais como as de Newton são, comumente, consideradas por estudantes como tendo o mesmo status de outras equações bem mais específicas como $\mathrm{S}=1 / 2 \mathrm{gt}^{2}$, válida apenas para a queda livre dos corpos. Uma das razões para esta confusão é que o ensino da Física, freqüentemente, dá muita atenção 
aos truques mencionados, deixando de lado as questões mais fundamentais como a modelagem dos fenômenos físicos que significa a aplicação das leis e dos conceitos fundamentais na construção de teorias com validades mais específicas. Por isso, na elaboração de simulações computacionais, uma atenção especial deveria ser lançada à modelagem que lhe dá suporte. Ao construir tais modelos, é necessário considerarem-se criticamente quais as características do sistema modelado que poderiam ser negligenciadas e quais aquelas que deveriam ser incluídas no modelo. Em qualquer caso, o valor educacional de uma simulação dependerá do fato de ela poder vir a representar para o estudante um papel de auxiliar heurístico e não apenas cumprir um papel algorítmico ou meramente ilustrativo (Härtel, 1997).

Muitos estudantes tendem a ver os programas computacionais que utilizam na aprendizagem da Física com poderes quase mágicos e como verdadeiras caixaspretas. Isso ocorre porque as simulações, por exemplo, são freqüentemente construídas com base em pressupostos ocultos para o estudante; e muitos desses pressupostos são ultra-simplificados, ou mesmo questionáveis. Dessa forma, tem-se argüido que experiências educacionais com simulações, muitas vezes, não servem de 'fermento' para o pensamento, como pretendido. Servem, sim, para embotá-lo (Oppenheimer, 1997). Elaboradas com uma tal característica, as simulações não podem ser facilmente avaliadas quanto aos seus domínios de validade e ao seu grau de representatividade em relação à realidade (Funke, 1998). Sérios problemas poderão ocorrer se uma simulação utilizada carregar imprecisões, pois os estudantes podem mesmo nunca vir a perceber a sua ausência de compreensão da situação real em causa (Russel, 2001). Um outro problema é que o crescente uso da Informática tem levado alguns professores a utilizarem simulações até mesmo para atividades que, de um modo mais sensato, não seriam absolutamente necessárias.

É preciso ter-se em mente que o ponto de partida de toda simulação é a imitação de aspectos específicos da realidade, isto significando que, por mais atraente que uma simulação possa parecer, ela estará sempre seguindo um modelo matemático desenvolvido para descrever a natureza, e este modelo poderá ser uma boa imitação ou, por outras vezes, um autêntico absurdo. Uma simulação pode tão somente imitar determinados aspectos da realidade, mas nunca a sua total complexidade. Uma simulação, por isso, nunca pode provar coisa alguma. O experimento real será sempre o último juiz.

Tomem-se, por exemplo, as modelagens tão comuns de sistemas atômicos. Como um computador tem uma memória finita, mesmo que gigantesca, as simulações, para serem factíveis, são realizadas com sistemas que, tipicamente, consideram a existência de $10^{2}$ a $10^{6}$ átomos, enquanto um sistema real tem algo da ordem de $10^{22}$ átomos. Por isso, extrapolações não tri- viais para sistemas bem maiores são sempre requeridas (Bergqvist, 2000).

Embora sejam os experimentos reais os indispensáveis juízes e a base para a construção do conhecimento, eles são, por vezes, altamente complexos e de difícil realização e compreensão. A complexidade de uma simulação, por outro lado, pode convenientemente ser adequada às necessidades reais dos estudantes e da situação de aprendizagem pretendida. Na impossibilidade da comparação com o real, a discussão da construção do modelo torna-se ainda mais importante e essencial.

A necessidade de uma discussão mais profunda sobre o uso conjunto de experimentos reais, sobre simulações computacionais e abordagens teóricas foi tratada, por exemplo, por Grosu (1996), no caso específico do estudo de um pêndulo cônico.

Críticos mais severos da utilização irrefletida da Informática na Educação têm chamado a atenção para o fato de que as simulações computacionais parecem limitar a possibilidade de os estudantes serem confrontados com a riqueza heurística da experiência dos erros experimentais e, assim, da tentativa de resolverem problemas da vida real (Kimbrough, 2000). Têm, igualmente, assinalado, de há muito, que os resultados nas simulações tendem a ser prédeterminados, em lugar de estarem abertos à pesquisa mais especulativa e aos raciocínios mais abertos (Prosser \& Tamir, 1990). A idéia central seria, portanto, pensar com a mente e calcular com o computador (Trampus \& Velenje, 1996).

Outros críticos mais otimistas com as possibilidades da Informática na Educação têm apontado que um problema geral no ensino da Física tem sido o uso precoce de símbolos e métodos matemáticos que atuam como uma barreira de entrada para muitos estudantes, conduzindo-os a uma experiência de insucessos e resignação. Certo é que as simulações computacionais oferecem o mesmo grau de exatidão daquelas matematizações. Contudo, a linguagem utilizada de gráficos animados parece mais diretamente acessível à maioria dos estudantes. As soluções apresentadas em tal linguagem podem atuar como uma etapa intermediária em direção à abstração; mas apenas intermediária. Elas permitem tratar um grande conjunto de problemas que pareceriam inacessíveis por métodos matemáticos tradicionais. Aquilo que pode ser aprendido parece, assim, ser ampliado de um modo mais suave sem a experiência tão freqüente do erro e da ansiedade causada pela busca das soluções. Mas parte desta ansiedade compõe um esforço heurístico que as simulações não incorporam. Assim, os entusiastas que tomam as simulações como uma panacéia para o ensino e a aprendizagem da resolução de problemas parecem não atentarem devidamente para a natureza da aprendizagem humana. As idas e vindas dos raciocínios exploratórios, os erros experimentais, as vacilações das situações reais; tudo isso, que é economizado em nome de uma didática da informação a ser 
veiculada, carrega latente um problema central, pois muito do que nós aprendemos na vida real é, também, sobre o como aprendemos e não apenas sobre o que aprendemos.

Uma questão igualmente disputada tem sido a da propalada capacidade de um ensino assistido por computador ser um tipo de educação que atenda às necessidades do indivíduo. Contudo, se o computador for introduzido nas escolas sem que haja mudanças estruturais nos métodos de ensino, no treinamento e nas expectativas dos professores e na própria estrutura administrativa da escola, o poder educacional dessas máquinas será bastante reduzido. Computadores podem ser usados para melhorar a produtividade, para ensinar habilidades básicas que envolvam prática, para fornecer alternativas aos livros didáticos e para deixar os professores mais livres e, assim, poderem ensinar aos seus estudantes a resolverem problemas específicos. Contudo, computadores não devem ser usados apenas para automatizar, ou mesmo, amplificar os erros do passado e do presente. É preciso observar que o computador pode tanto encorajar brilhantes práticas de estudo quanto outras bem menos refletidas (Oppenheimer, 1997).

Defensores mais otimistas do uso das simulações na educação têm creditado a elas um potencial de atuarem decisivamente na mudança conceitual (Snir, 1988; Sassi, 1996). Cabe, entretanto, notar que nem a realização de experimentos reais pode garantir qualquer mudança conceitual, tal a riqueza das interpretações possíveis de variados aspectos da realidade. No caso do uso de simulações, as restrições são ainda maiores, pois elas estão baseadas, como já apontado, em modelos que contêm necessários pressupostos que simplificam a realidade, e o funcionamento do software é proporcionado por um banco de dados que pode ser grande; mas que, apesar disso, é limitado e não infinito.

O potencial do computador em personalizar o ensino da Física foi estudado por Yeo et al. (1998) observando as interações de estudantes com uma simulação de movimento de projéteis. Eles registraram em vídeo que quando os estudantes eram deixados a sós com o computador, suas interações com o conteúdo do programa eram limitadas e que eles moviam-se, prematuramente, para as próximas telas ou gráficos. Quando os pesquisadores pediram aos estudantes para explicarem as suas observações, dois pontos ficaram evidentes: eles mantinham as suas concepções alternativas sobre o movimento dos projéteis e apenas seguindo as sugestões dos pesquisadores notaram e tentaram interpretar aspectos mais abstratos do programa. Sem a intervenção de um professor, os estudantes não se engajavam cognitivamente em um nível profundo, nem sempre liam nem seguiam todas as instruções, nem relacionavam os gráficos ao texto. Benito e Ferrn (1996), por sua vez, pesquisaram onde estavam focalizadas as mentes de professores e de estudantes, ao lidarem com simulações no ensino da Física. Suas conclusões são se- melhantes às de Yeo et al. acima mencionadas, tendo os autores concluído ainda que apenas professores podem explicar idéias e transmitirem certas visões da realidade física, criticamente.

Parece não haver dúvida de que a aprendizagem que vá além da pura memorização deve estar baseada em atividades nas quais o aprendiz se envolva cognitivamente. O conhecimento não pode ser simplesmente implementado ou transferido, ele precisa ser construído e reconstruído para ter qualquer efeito duradouro. Não existe dúvida de que a aprendizagem na interação com seres humanos, com um professor real, é uma necessidade indispensável em muitos casos. Simulações podem ser ricas em imagens e em cálculos; mas são pobres em sua dimensão social (Funke, 1998).

\section{Conclusões}

Do amplo quadro de argumentações acima traçado, podem-se confrontar as muitas vantagens atribuídas para as simulações computacionais no ensino da Física com as não menos numerosas limitações, igualmente apontadas. É imprescindível que não se deixe de considerar os dois lados da questão: as vantagens e as limitações de um tal uso.

Por mais encantadoras que possam parecer as simulações computacionais, com suas cores, movimentos e sons, é preciso levar em conta que elas não são, provavelmente, a via de acesso principal para os raciocínios não verbais. Os movimentos corporais, o tato, a manipulação de objetos reais, a construção de relacionamentos no mundo físico estão também entre os seus principais fundamentos. O problema é que, na Educação tradicional, os sentidos têm desempenhado um papel secundário após o jardim da infância (Healy, 1999).

Apesar de todas as críticas, entretanto, há de admitir-se que boas simulações, criteriosamente produzidas, existem e que os professores guardam uma expectativa muito grande do potencial de suas utilizações. É preciso que fique bem claro que a argumentação levantada neste artigo não deve levar à conclusão de que os seus autores advogam o abandono da Informática Educacional, mas apenas que apontam para a necessidade de uma utilização da mesma mais refletida, equilibrada e nunca exclusiva. O ato educativo é por demais complexo para que o profissional da educação em Física possa optar por um único recurso pedagógico. $\mathrm{O}$ ato educativo deveria, ao contrário, ser focalizado de uma forma holística em múltiplas possibilidades trazidas pela realidade concreta, pela interação humana e, também, pelas simulações. Computadores podem ser excelentes coadjuvantes, mas não são bons substitutos da experiência com o mundo real (Burg \& Cleland, 2001). É preciso ter em conta que a educação não é algo que envolve apenas a informação. Educar consiste, igualmente, em fazer as pessoas pensarem sobre 
a informação e a refletirem criticamente. A Educação vista de uma forma holística, lida com a compreensão, com o conhecimento e com a sabedoria. É preciso estimular as mentes dos nossos estudantes e não apenas abarrotá-las de informações, de imagens enlatadas. Mario Schemberg costumava dizer que por vezes o volume das informações coletadas abafa a luz do pensamento crítico. Em uma época na qual a Informática na Educação parece algo quase inquestionável, é preciso lembrar sempre desta mensagem ou mesmo resgatar as palavras ainda mais antigas de T.S. Eliot (1962, p. 107):

"Onde está a sabedoria que perdemos com o conhecimento?

Onde está o conhecimento que perdemos com a informação?"

\section{Referências}

BASER, B. Use of PC's in Students Laboratories. Proceedings of the GIREP-ICPE-ICTP International Conference: New Ways of Teaching Physics. Ljubjana, Slovenia, 21/8 a 27/8 de 1996.

BENITO. L. FERRN, J. Computers, a Teaching Physics Problem? Proceedings of the GIREP-ICPEICTP International Conference: New Ways of Teaching Physics. Ljubjana, Slovenia, 21/8 a 27/8 de 1996. BERGQVIST, L. (2000). Monte Carlo Simulations of Ferromagnetic Quasi Two Dimensional Spin Model Systems. Master of Science Thesis. Uppsala University. BURG, J. \& CLELAND, B. Computer-Enhanced or Computer-Enchanted? The Magic and Mischief of Learning With Computers. Interactive Multimedia Electronic Journal of Computer Enhanced Learning. Wake Forest University. Abril 2001.

EDWARD, N. An Evaluation of Student Perceptions of Screen Presentations in Computer-based Laboratory Simulations. European Journal of Engineering Education; v22 n2 p143-51 Jun 1997.

ELIOT, T. S. "Choruses from The Rock", Selected Poems, New York: Harvest, Harcourt, 1962, p.107.

FUNKE, J. (1998) Computer-Based Testing and Training with Scenarios from Complex Problem-Solving Research: Advantages and Disadvantages. International Journal of Selection and Assessment, 6, 90-96.

GADDIS, B. (2000).Learning in a Virtual Lab: Distance Education and Computer Simulations. Doctoral Dissertation. University of Colorado.

GROSU, I. Ideal Teaching and Learning: Experiment, Computer Experiment and Theory. Proceedings of the GIREP-ICPE-ICTP International Conference: New Ways of Teaching Physics. Ljubjana, Slovenia, 21/8 a $27 / 8$ de 1996 .

HARTEL, H. Didactical Potential of Simulations. http:

//www.colos.ec-lyon.fr/theory/didactic/simulation.html. 1997 .
HEALY, J. Endangered Minds: Why Children Don't Think and What We Can Do About It. 1999. New York: Touchstone Books.

KAMISHINA, Y. Learning Parametric Excitation with Computer Simulation and True Experiment. Proceedings of the GIREP-ICPE-ICTP International Conference: New Ways of Teaching Physics. Ljubjana, Slovenia, 21/8 a 27/8 de 1996.

KIMBROUGH, D. (2000). Can we go the distance in chemistry? Reflections on distance learning laboratories. Strategies for Success, 33, 3-4.

KOCIJANCIC, S. Collection of Computer Based Experiments. Proceedings of the GIREP-ICPE-ICTP International Conference: New Ways of Teaching Physics. Ljubjana, Slovenia, 21/8 a 27/8 de 1996.

LIKAR, A. \& KOZUH, V. Animated Physics. Proceedings of the GIREP-ICPE-ICTP International Conference: New Ways of Teaching Physics. Ljubjana, Slovenia, 21/8 a 27/8 de 1996.

MARINO, T., VIOLINO, P. \& CARPIGNANO, G. A New Interface Card for the Physics Lab. Proceedings of the GIREP-ICPE-ICTP International Conference: New Ways of Teaching Physics. Ljubjana, Slovenia, 21/8 a 27/8 de 1996.

MARTINS M., PEREIRA, M. \& MARTINS, N. Computer Based Training in University Education. Proceedings of the GIREP-ICPE-ICTP International Conference: New Ways of Teaching Physics. Ljubjana, Slovenia, 21/8 a 27/8 de 1996.

MIRO-JULIA, J. Dangers of the Paradigm Shift. Draft Article. Departament de Matemàtiques i Informàtica. Universitat de les Illes Balears.

http://dmi.uib.es/people/joe/opinion/ParShfDgr.html. OPPENHEIMER, T. The Computer Dilusion. The Atlantic Monthly. Volume 280, No. 1; 45-62. (July 1997). PROSSER, M. \& TAMIR, P. (1990). Developing and Improving the Role of Computers in Student Laboratories. In E. Hegarty-Hazel (Ed.), The StudentLlaboratory and the Science Curriculum (pp. 267-290). London: Routledge.

REUSCH, W. Combining Measurement and Modelling Using Graphics Editor. Proceedings of the GIREPICPE-ICTP International Conference: New Ways of Teaching Physics. Ljubjana, Slovenia, 21/8 a 27/8 de 1996.

ROGERS, L. The Use of Software to Explore Experimental Data. Proceedings of the GIREP-ICPEICTP International Conference: New Ways of Teaching Physics. Ljubjana, Slovenia, 21/8 a 27/8 de 1996. RUSSEL, G. Computer Mediated School Education and the Web. First Monday, volume 6, number 11 (November 2001).

SASSI, E. Addressing Some Common Learning/Teaching Difficulties in Basic Physics Courses through Computer Based Activities. Proceedings of the GIREP-ICPE-ICTP International Conference: New Ways of Teaching Physics. Ljubjana, Slovenia, 21/8 a 
27/8 de 1996.

SCHECKER, H. System Dynamics Modeling in Physics - Educational Rationale.

http://www.physik.uni-bremen.de/physics.education/ niedderer/projects/cip/modeling2.html. 2001.

SMITH, S. Electronics in Education: Impact of Technology on Curriculum, Teaching, and Learning. Technical Report. Science Council of Canada, Ottawa (Ontario).

SNOJ, R. Computer Simulation of Fraunhofer Diffraction Patterns with Visual Light and Comparision between Experiments and Simulation. Proceedings of the GIREP-ICPE-ICTP International Conference: New Ways of Teaching Physics. Ljubjana, Slovenia, 21/8 a $27 / 8$ de 1996.

SNIR, J. et al (1988). The Truth, but Not the Whole Truth: An Essay on Building a Conceptually Enhanced Computer Simulation for Science Teaching. Draft Article. Technical Report 88-18. MIT, Cambridge, USA. SOEGENG, R. Simple Simulation in Physics Education. Proceedings from the 4 th Australian Computers in Physics Education Conference. Freemantle. 27 Set 2 Oct 1998.

SPERANDEO-MINEO, R. Computer Simulations for a Statistical Approach to the Entropy Concept. Proceedings of the GIREP-ICPE-ICTP International Conference: New Ways of Teaching Physics. Ljubjana, Slovenia, $21 / 8$ a $27 / 8$ de 1996.

TRAMPUS, M. \& VELENJE, G. Let Computers Compute - Mathcad and Word in Secondary School Physics. Proceedings of the GIREP-ICPE-ICTP International
Conference: New Ways of Teaching Physics. Ljubjana, Slovenia, 21/8 a 27/8 de 1996.

VEDELSBY, P. Is it 'Good Physics'? Proceedings of the GIREP-ICPE-ICTP International Conference: New Ways of Teaching Physics. Ljubjana, Slovenia, $21 / 8$ a $27 / 8$ de 1996 .

VERBIC, S. Different Conceptions of the Same Physical Phenomenon for Real and Numerical Experiment. Proceedings of the GIREP-ICPE-ICTP International Conference: New Ways of Teaching Physics. Ljubjana, Slovenia, 21/8 a 27/8 de 1996.

VOLD, P., GJESSING, K. \& HERNES, A. ElPed: an Interactive PC-Based Learning Program for Basic Electrical Circuits. Proceedings of the GIREP-ICPEICTP International Conference: New Ways of Teaching Physics. Ljubjana, Slovenia, 21/8 a 27/8 de 1996.

VRANKAR, L. Computer Games and Physics. Proceedings of the GIREP-ICPE-ICTP International Conference: New Ways of Teaching Physics. Ljubjana, Slovenia, 21/8 a 27/8 de 1996.

YEO, S.; LOSS, R.; ZADNIK, M.; HARRISON, A. \& TREAGUST, D. (1998). What do Students Really Learn from Interactive Multimedia: a Physics Case Study. Proceedings of the 4 th Australian Computers in Physics Education Conference. Freemantle, Australia. 27 Set - 2 Out 1998.

ZOECHLING, J. The Austrian Physics-Computer. Proceedings of the GIREP-ICPE-ICTP International Conference: New Ways of Teaching Physics. Ljubjana, Slovenia, $21 / 8$ a $27 / 8$ de 1996. 